revista do ieb n 45 p. 87-106 set 2007

\title{
Regina Gomide Graz: modernismo, arte têxtil e relações de gênero no Brasil'
}

\author{
Ana Paula Cavalcanti Simioni ${ }^{2}$
}

\section{Resumo}

0 artigo pretende discutir o modo como a disciplina história da arte é perpassada pela dimensão do gênero, particularmente em se tratando das obras de arte têxteis, tradicionalmente menos valorizadas por serem associadas a faturas e meios "naturalmente” femininos. Tal caso é esclarecedor do quanto, historicamente, a disciplina baseia-se em uma hierarquia de objetos que é construída mediante categorias que transcendem os limites do que é "puramente estético". A trajetória de Regina Gomide Graz - a introdutora das artes têxteis modernas no Brasil - permitenos pensar a gênese das categorias valorativas e a maneira como, concretamente, as artistas do sexo feminino puderam negociar posições específicas dentro dos circuitos modernistas, lidando com diversas ordens de injunções sociais, como as limitações colocadas pelas parcerias artísticas, a divisão sexual do trabalho daí decorrente e os discursos socialmente disseminados sobre o que constituía uma arte "feminina".

\section{Palavras-chave}

Regina Gomide Graz, arte têxtil, gênero, modernismo, art déco, sociologia da arte.

1 Este artigo é fruto da pesquisa que venho desenvolvendo como docente da Escola de Artes, Ciências e Humanidades da Universidade de São Paulo. Muitos dos dados aqui analisados só puderam ser obtidos mediante o inestimável apoio da FAPESP que me concedeu, entre janeiro e fevereiro de 2006, uma bolsa para realização da pesquisa nos arquivos de Genebra, Suiça. Sou ainda profundamente grata a Annie Graz que, muito amavelmente, cedeume uma documentação inédita sobre a artista Regina Gomide Graz, a qual pertence ao acervo do Instituto John Graz. Sem esses dois apoios a pesquisa teria sido impossivel.

2 Doutora em Sociologia pela USP, docente da Escola de Artes, Ciências e Humanidades da Universidade de São Paulo. 
revista do ieb n 45 p. 87-106 set 2007

\title{
Regina Gomide Graz: modernism, textile art and gender relations in Brazil
}

Ana Paula Cavalcanti Simioni

\begin{abstract}
This article addresses how the discipline of art history is pervaded by gender issues, particularly in respect to textile works of art, which are traditionally less valued due to their association with craftsmanship and means identified as 'feminine in nature'. This case enlightens how historically, the discipline is based upon a hierarchy of objects, construed by categories that transcend the limits of what is 'purely aesthetic'. The life and work of Regina Gomide Graz - who introduced modern textile arts in Brazil - allows us to reflect upon the origins of categories of value (in the discipline of art history) and the way in which women artists were able to, concretely, negotiate positions within the modernist artistic circle, by dealing with diverse forms of social injunctions, such as the restrictions posed by artistic partnerships, and the consequent sexual division of labor, as well as socially widespread discourses on what constituted a 'feminine' art.
\end{abstract}

\section{Keywords}

Regina Gomide Graz, textile art, gender, modernism, art déco, sociology of art. 
0 presente artigo aborda as relações entre história da arte e dinâmicas de gênero no campo artístico brasileiro a partir de um estudo de caso, o de Regina Gomide Graz (1897-1973). Uma das artistas mais produtivas no meio artístico nacional durante as décadas de 1920 a 1940, Regina Graz atuou como pintora, decoradora e tapeceira. Sua relevância para as artes plásticas brasileiras foi considerável, tendo sido ela uma das introdutoras do estilo art déco, além de ter atuado no sentido de promover a autonomização das artes decorativas ${ }^{3}$.

A opção pelas artes aplicadas era incomum no país, tendo em vista a costumeira valorização dos suportes artísticos tradicionais, como a pintura e a escultura, que seguia o corolário estabelecido pela hierarquia acadêmica. Mesmo dentro dos circuitos modernistas, nos quais tal conjunto de valores já não predominava, as artes puras permaneceram mais apreciadas, quanto mais se comparadas àquelas realizadas em suportes têxteis. Tapetes, almofadas, bordados, cortinas e vestidos foram artefatos que raramente passaram por aquela "alquimia”, tão central ao campo artístico, por meio da qual alguns objetos distinguem-se dos demais, a eles sendo agregada uma carga de valores e prestígios que possibilita descrevê-los, nomeá-los e defini-los como "artísticos" . Neste artigo, pretendo discutir as razões da depreciação sucessiva das artes têxteis no campo artístico e o modo como isso determinou uma posição secundária para Regina Graz. A história da arte é tomada como uma prática discursiva perpassada pelas dinâmicas de gênero; prática essa que se cristaliza na maneira como são historicamente construídas as suas categorias valorativas e as hierarquias que

3 Por autonomização das artes decorativas compreende-se a afirmação do gênero enquanto uma modalidade específica e reconhecida de arte. Para maiores informações sobre a questão, particularmente no que tange às artes têxteis, consultar: CÁURIO, Rita. Artêxtil no Brasil: viagem pelo mundo da tapeçaria. Rio de Janeiro: Ed. do Autor, 1985.

4 A compreensão de arte aqui adotada deriva dos escritos de Pierre Bourdieu, para quem “o produtor do valor da obra de arte não é o artista, mas o campo de produção enquanto universo de crença que produz o valor da obra de arte como fetiche ao produzir a crença no poder criador do artista. Sendo dado que a obra de arte só existe enquanto objeto simbólico dotado de valor se é conhecida e reconhecida, ou seja, socialmente instituída como obra de arte por espectadores dotados da disposição e da competência estéticas necessárias para a conhecer e reconhecer como tal, a ciência das obras tem por objeto não apenas a produção material da obra, mas também a produção do valor da obra ou, o que dá no mesmo, da crença no valor da obra”. BOURDIEU, P. As regras da arte. Gênese e estrutura do campo literário. São Paulo: Companhia das Letras, 1996. p. 259. 
definem os próprios objetos sobre os quais se debruça enquanto disciplina ${ }^{5}$.

\section{Arte têxtil, arte feminina?: a história da arte e suas exclusões}

Nos escritos sobre Regina Gomide Graz, duas afirmações, que acabam por se conjugar, sempre sobressaem: a de a artista ter realizado obras "femininas”, o que implica afirmar que as artes têxteis eram (e são) percebidas de um modo sexuado; e a de ser descrita como "esposa" e "irmã" de artistas (respectivamente, de John Graz e Antonio Gomide), o que a coloca em uma posição secundária, de "colaboradora" mais do que propriamente de "autora".

Analisando a relevância histórica de suas obras, Aracy Amaral destaca que "Regina Graz traria em sua bagagem de formação européia, uma atividade inédita para as mulheres de S. Paulo, e da qual seria pioneira: a das artes decorativas."7 Ainda que o artigo apresente contribuições fundamentais para o conhecimento da produção da artista em seu contexto, é preciso interrogar as evidências: por que as obras de Regina Graz e, em um sentido mais amplo, as artes aplicadas são tomadas como naturalmente femininas? A partir de quando e por quais motivos as obras de arte decorativas passaram a ser percebidas como práticas de mulheres? E quais as conseqüências de tais apreciações?

5 Para uma reflexão mais aprofundada sobre as interferências das questões de gênero na história da arte e seus efeitos, consultar: POLLOCK, Griselda. Vision \& difference: feminity, feminism and the histories of art. Londres: Routledge, 1994; BROUDE, Norma; GARLAND, Judith. Feminism and art history: questioning the litany. New York: Harper \& Row Publishers, 1982.

6 Freqüentemente, os vínculos familiares e afetivos de artistas mulheres com colegas de profissão acarretaram o desprestígio de suas produções e, conseqüentemente, de suas trajetórias. Foram elas compreendidas e descritas pela crítica e pela historiografia como "esposas", "companheiras”, "irmãs", "amantes" ou "filhas" de artistas, um modo de, sutilmente, negar-lhes o direito à autoria, justamente a afirmação mais valiosa no campo das artes e da cultura. Sobre a dinâmica das parcerias e o impacto das mesmas sobre as trajetórias das escritoras brasileiras, consultar, ELEUTERIO, Maria de Lourdes. Vidas de romance. Rio de Janeiro: Toopbooks, 2005. Sobre as parcerias, comumente desiguais, entre os casais (heterossexuais e homossexuais) de artistas visuais, consultar: CHADWICK, W.; DE COURTIVRON, I. (Org.). Amor \& arte. Duplas amorosas e criatividade artística. Rio de Janeiro: Jorge Zahar, 1995.

7 AMARAL, Aracy. Às margens de uma pesquiza: os artistas da Semana de Arte Moderna. Mirante das artes, São Paulo, n. 8, p. 11-12, mar./abr. 1968. Vale notar que a pesquisadora é uma das poucas a terem dedicado um artigo exclusivamente à obra da artista, merecendo o texto atenção. 
Desde os anos 1970, a história da arte feminista aponta que a inexistência de nomes femininos canônicos deve-se não a ausências naturais de qualidades intelectuais ou artísticas, mas sim a uma prática sucessiva, mais ou menos institucionalizada, de exclusão das mulheres do campo artístico. Dentro do sistema acadêmico, elas enfrentaram um obstáculo bastante concreto: o de não serem aceitas nas academias de belas artes. Linda Nochlin, em um consagrado artigo - "Why have there been no great women artists" ${ }^{-}$, mostrou que os impedimentos institucionais (e não os supostos limites "naturais") constituíam a chave para a compreensão da inexistência de pintoras e escultoras notáveis. 0 que gerou tal exclusão foi, ao seu ver, o fato de as aspirantes às carreiras artísticas terem sido impedidas de cursarem as aulas de modelo vivo desde as primeiras academias e, como conseqüência, de não dominarem as principais habilidades exigidas aos artistas acadêmicos. Mesmo com o declínio do academismo, novos mecanismos de diferenciação com base no gênero continuaram a operar. No caso enfocado neste artigo, busca-se compreendê-los nos espaços concretos que as mulheres ocuparam dentro dos pequenos grupos de artistas - unidos por aquilo que Raymond Williams chamou de "estrutura de sentimento"9-, nos quais se constituiu um novo tipo de prática artística, menos alicerçada em instituições, a qual denominamos, de modo abrangente, Modernismo ${ }^{10}$.

Dentro desses pequenos grupos vinculados por objetivos estéticos e experiências vividas em comum, foram recorrentes as parcerias, artísticas e conjugais. Sonia e Robert Delaunay; Camille Claudel e Ausguste Rodin; Fraz Arp e Sophie Tauber-Arp; Diego Rivera e Frida Kahlo; Hannah Höch e Raoul Hausmann; Vanessa Bell e Duncan Grant; Lee Krasner e Jackson Pollock e, no espaço nacional, Tarsila e Oswald de Andrade são alguns dos muitos exemplos. Para a plena compreensão do mecanismo

8 NOCHLIN, Linda. Why have there been no great women artists? In: HESS, Thomas B. Art and sexual politics. Nova Iorque: Macmillan Publishing, 1973. p. 1-43.

9 A idéia de uma estrutura de sentimentos sobre a qual se alicerçam e formam as identidades do grupo de artistas ingleses, em contraposição à de outros grupos, foi desenvolvida por WILLIAMS, Raymond. A fração Bloomsbury. Revista Plural, São Paulo, n. 6, p. 139-167, 1999. Uma análise instigante a partir da noção de estrutura de sentimento e sua articulação com a divisão dos papéis sexuais dentro dos círculos intelectuais brasileiros é feita por PONTES, Heloísa. Destinos mistos: os críticos do Grupo Clima em São Paulo, 1940-68. São Paulo: Companhia das Letras, 1998.

10 Sobre as várias e complexas definições de Modernismo consultar: HARRISON, Charles. Modernismo. São Paulo: Cosac \& Naify, 1996. 
de funcionamento de tais parcerias, via de regra envolvidas em projetos de vanguarda, e de como as identidades pessoais e artísticas foram nelas geradas, é fundamental que se observem as posições diversas ocupadas por homens e mulheres dentro daqueles pequenos círculos e a forma com que as artistas negociaram $^{11}$ seus espaços, não raro inferiores e dominados, no interior dos mesmos ${ }^{12}$.

No Brasil, um dos casos mais representativos de divisão sexual do trabalho dentro dos círculos modernistas é o de John e Regina Graz ${ }^{13}$. Ambos se conheceram em Genebra, cidade para a qual a família de Regina transferiu-se entre 1913 e 1920, em decorrência da nomeação de seu pai, Gabriel Gonçalves Gomide, ex-Ministro do Tribunal de Contas da União, para um cargo diplomático $^{14}$. No ano de sua chegada, Regina, Antonio e Maria Gomide inscreveram-se na École des Beaux Arts de Genebra,

11 A idéia de negociação com que trabalho aqui foi retirada dos escritos de BECKER, Howard. Art worlds. Berkley: University of California Press, 1982. Para o autor, o mundo da arte é fruto de uma prática coletiva conformada por regras construídas por meio das interações de agentes concretos. Ou seja, estes indivíduos lidam com as determinações do contexto de um modo ativo e não apenas se sujeitando docilmente às regras impostas. No caso das mulheres, isso significa perceber que estas, por mais que enfrentassem obstáculos concretos para se afirmarem como artistas, possuíam capacidade de intervir, modificar e mesmo recriar sua própria condição dentro de um contexto determinado.

120 já mencionado livro de CHADWICK, W.; DE COURTIVRON, I. (Org.). Amor Et arte. Duplas amorosas e criatividade artística. Rio de Janeiro: Jorge Zahar, 1995, explora bem tais questões, embora nas análises dos casos perceba-se uma acentuada tendência à vitimização das artistas, como se praticamente inexistisse qualquer tipo de possibilidade para que essas negociassem suas posições dentro das parcerias artísticas e conjugais nas quais estavam envolvidas. Já o livro de PERRY, Gill. Women artists and the parisian avant-garde. Manchester: Manchester University Press, 1995, demonstra o modo como as algumas artistas lograram, de modo ativo e inventivo, conquistar para si espaços próprios de atuação, ampliando suas participações naqueles circuitos artísticos modernistas - predominantemente, mas não exclusivamente - masculinos.

13 A história da arte tende a considerar a produção de John e Regina Graz atrelada à do irmão da artista, Antonio Gomide, chamando-os de "tríade de artistas-decoradores”. Tal posição necessita, porém, ser matizada na medida em que os documentos sobre os projetos decorativos realizados entre os anos 1920, 30, 40 e 50 não mostram a participação de Antonio, cabendo sim a John a idealização dos conjuntos e a dos materiais “sólidos” e a Regina a produção têxtil.

14 Notícias biográficas sobre Regina e John Graz podem ser encontradas, entre outros em FERNANDES, Luis Felipe. John Graz. Rio de Janeiro: Editora Internacional, 1985. 
da qual John já era aluno de relativo destaque ${ }^{15}$. Em breve, começaram a namorar e, em 1920, quando a família retornou ao Brasil, John, a esta altura já unido a Regina, transferiu-se para São Paulo. 0 casal fixou-se na cidade no começo dos anos 20, sendo rapidamente absorvido pelo círculo dos jovens artistas responsáveis pela Semana de 1922, da qual participaram, John com algumas telas, Regina com tapetes em estilo art déco. A partir de 1923, dedicaram-se, conjuntamente, às artes aplicadas, especialmente à construção de elegantes e complexos projetos decorativos para as elites paulistas, até 1950 .

Conforme apontou Sergio Miceli, as múltiplas tarefas envolvidas para a plena realização de tais obras eram repartidas mediante um critério baseado em uma analogia entre o gênero do autor e os gêneros da produção. Com isso, os gêneros mais "altos" como a criação de móveis, luminárias, painéis e afrescos eram entregues aos homens. Já as mulheres - Regina e sua irmã Beatriz Gomide Witecy - eram incumbidas de realizar as almofadas e cortinas, ou seja, trabalhos percebidos como mais "delicados", comumente associados às prendas do lar e ao reino do feminino ${ }^{16}$. Vale ainda ressaltar que cabia a John a idealização de toda a produção, a parte intelectual do projeto, enquanto Regina encarregava-se do que havia de supostamente mais secundário e desvalorizado na empreitada: a mera execução das tarefas, a manufatura envolvida no processo.

A dupla atualizava no Brasil alguns padrões de divisão do trabalho artístico existentes anteriormente. Na tradição ocidental, as artes aplicadas ocupavam um espaço inferior, o qual foi paulatinamente feminilizado ${ }^{17}$. A gênese dessa posição encontra-se no Renascimento, em especial nos estudos de G. Vasari, autor das pri-

15 Segundo a documentação encontrada nos Archives de la Terrassière, John Graz foi um aluno notável, obtendo média 6,0, a nota máxima, na maior parte das disciplinas que cursou entre 1907 e 1910 (para maiores informações sobre o período em que John foi aluno da EBA, consultar: 1992 va32.47. Boîte de fiches d'élèves, 1900-1940). Além disso, recebeu outros prêmios que mostravam tratar-se de artista de grande potencial e em ascensão: em 1916, foi vencedor de um concurso promovido na Suiça no qual obteve uma pensão da fundação Théodore Lissignol; em 1917 vence outro concurso, desta vez de cartazes, promovido pela Société des Jeunes Commerçants de Lausanne. As informações a respeito estão nos Archives Cantonales Vaudoises, na revista L'Oeuvre: Revue Mensuelle, n. 2, ago. 1917.

16 A esse respeito consultar: MICELI, Sergio. Nacional estrangeiro: história social e cultural do modernismo artístico em São Paulo. São Paulo: Companhia das Letras, 2003. p. 189.

17 Tal tema é discutido por CHADWICK, Witney. Women, art and society. Londres: Thames and Hudson, 1996. 
meiras categorias fundadoras da moderna história da arte. Segundo seus escritos, considerava-se digno do nome artista o indivíduo dotado de capacidades intelectuais que o distinguissem dos contemporâneos, configurando um estilo próprio. Estipulava-se a atividade artística como algo individual, fruto de trabalho intelectual, e que conferia superioridade ao criador. A distinção pautava-se por um padrão de habilidade técnica proveniente das grandes artes, a partir de então definidas como todas aquelas baseadas no disegno: a pintura, a escultura e a arquitetura. As outras artes passavam a ser consideradas inferiores, associadas ao artesanato, termo que adquiria um sentido negativo, compreendendo produções coletivas nas quais não se fazia necessário o conhecimento do desenho, configurando trabalhos mais manuais do que intelectuais, a saber, característicos dos procedimentos de produção presentes nas guildas ${ }^{18}$. Tal diferenciação agravou-se com a criação da Academia francesa, que, passando a deter o monopólio do estudo do modelo vivo - cujo conhecimento era central para as pinturas de história e para os retratos, gêneros que ocupavam o cume da hierarquia acadêmica -, destituiu as corporações dos meios adequados para a formação dos $\operatorname{artistas}^{19}$. Nesse momento, a imagem do artista aplicado atrelouse definitivamente à do artesão, visto então como o protótipo do trabalhador manual em que estão ausentes dotes intelectuais.

Outro estigma que pairava sobre as artes aplicadas era o de serem dominadas pelo trabalho feminino. Novamente, o fato de terem sido as mulheres excluídas das academias - e, portanto, do acesso ao modelo vivo - foi determinante, pois em sua maioria elas só estavam aptas a realizar os chamados gêneros "menores": os retratos, as miniaturas, as pinturas em porcelana, as pinturas decorativas (vãos, esmaltes etc.), as aquarelas, as naturezas-mortas e, finalmente, toda a sorte de artes aplicadas, particularmente as tapeçarias e bordados. Tais modalidades foram sendo, aos poucos, feminilizadas, isto é, as obras consideradas inferiores tornaram-se imediatamente vinculadas às práticas artísticas de mulheres. De modo que, ao longo do século XIX, montou-se o seguinte círculo vicioso: as mulheres, seres intelectualmente inferiores, eram vistas como capazes de realizar apenas uma arte feminina, ou seja, obras menos significativas do que aquelas feitas pelos homens geniais: as grandes telas e esculturas históricas ${ }^{20}$. Gêneros outrora valorizados, como a tapeçaria e o bordado, centrais durante a Idade Média,

18 GOLDSTEIN, Carl. Teaching academy. Academies and schools from Vasari to Albers. Cambridge: Cambridge University Press, 1996.

19 PEVSNER, Nicolau. As academias de arte. São Paulo: Companhia das Letras, 2005.

20 GARB, Tamar. L'Art féminin: the formation of a critical category in late nineteenth-century France. Art History, London, v. 12, n. 1, p. 39-65, mar. 1989. 
passaram, ao longo da Idade Moderna, a comportar duas cargas simbólicas negativas: a do trabalho feminino (logo, inferior), e a do trabalho manual (a cada dia mais desqualificado) ${ }^{21}$.

No que diz respeito à arte têxtil, ramo ao qual se dedicou Regina Graz, os estudos sobre a mais emblematicamente moderna e revolucionária escola de artes e design ocidental - a Bauhaus - mostram que os princípios norteadores por ela adotados alteraram muito pouco as relações entre os gêneros. As mulheres foram sistematicamente desencorajadas a cursarem os ateliês mais importantes da escola, como o de arquitetura e pintura, ao passo que o ateliê de tecelagem, menos prestigiado, foi praticamente freqüentado com exclusividade pelo sexo feminino ${ }^{22}$. Segundo Magdalena Droste,

[...] pode-se concluir que a Bauhaus de Weimar dificultou fundamentalmente a entrada das mulheres e que quando elas venciam os primeiros obstáculos, eram enviadas para a tecelagem.

Muito do que as mulheres da altura produziam de artístico era rejeitado pelos homens como sendo 'feminino' ou 'artesanal'. Os homens receavam uma tendência demasiado 'decorativa' e viam o objectivo da Bauhaus, a arquitectura, em perigo. ${ }^{23}$

A feminilização dos meios têxteis, bem como a associação do gênero às atividades menos intelectualizadas dentro do campo artístico (como artesanato, por exemplo), não devem ser naturalizados. Sua gênese encontra-se no modo como a sociedade capitalista do século XIX foi, por meio de práticas diversas, sucessivamente destituindo o trabalho no ramo têxtil de sua condição de criação, reduzindo-no a uma tarefa mecânica, a um labor. Na História geral da economia, publicada em 1919, período de inauguração de Bauhaus, o sociólogo Max Weber descreveu a

21 Sobre tal questão ler: NEWDIGATE, Ann. Arte kinda, tapicería sorta: los tapices como acceso em abreviatura a los lenguajes, definiciones, instituciones, actitudes, jearquías, ideologías, construcciones, clasificaciones, historias, prejuicios y otras malas costumbres de Occidente. In: DEPPEWEEL, Katy (Ed.). Nueva crítica feminista de arte: estrategias criticas. Madri: Ediciones Cátedra, 1998. Ver também ROSENQVIST, Johabba. Transgressing the border of textile art, or - swedish artists as craftsmen? In: EUROPEAN FEMINIST RESEARCH CONFERENCE, 5., 2003. Suécia: Lund University, 2003.

220 livro de WELTGE, Sigrid Wortmann. Women's work. Textile art from the Bauhaus. Londres: Thames and Hudson, 1993 analisa minuciosamente os mecanismos de gêneros operantes na Bauhaus e o modo com que, sucessivamente, o ateliê de tecelagem foi sendo feminilizado e subvalorizado dentro da escola.

23 DROSTE, Magdalena. Bauhaus, 1919-1933. Londres: Taschen, 2004. p. 40. 
diferença entre as profissões "masculinas”, como a medicina, na qual o trabalho teria um componente espiritual ou mágico, e os trabalhos "femininos", como a tecelagem da seda, ou a produção têxtil para as indústrias domésticas, considerados formas puras de "labor". Em sua teoria, as fábricas têxteis - que, como se sabe, empregavam majoritariamente mão-de-obra feminina - constituíram o primeiro exemplo histórico concreto do trabalho alienado. Nelas, os operários (ou operárias, seria mais apropriado dizer) foram definitivamente destituídos da capacidade de projetarem os objetos finais e da posse dos instrumentos de produção, ficando encarregados da simples execução braçal de tarefas repetitivas. $\mathrm{Na}$ margem oposta dessa figura emblemática do trabalho alienado encontrava-se, justamente, a imagem potente (e masculina) do artista, sujeito de todas etapas de seu próprio trabalho, desde a concepção da idéia até o objeto final de sua criação, passando pela propriedade e uso livre dos meios da produção ${ }^{24}$.

Pode-se então compreender porque mesmo dentro dos circuitos modernistas prevalecesse certa ambigüidade na consideração das obras têxteis enquanto objetos "artísticos". Na Bauhaus, uma série de polarizações evidenciava as dimensões valorativas que contrapunham os campos. De um lado, figuravam os ateliês mais nobres - aqueles considerados industriais, como os de vidro e de metais, nos quais os produtos eram modernos, feitos por designers, que englobavam os alunos da instituição; de outro lado, estavam os ateliês marginalizados, cujo trabalho era mais manual e tradicional, como os de cerâmica e de tecelagem, tidos como mais artesanais e apropriados para as artistas do sexo feminino ${ }^{25}$. Assim, a escola reiterava a tradição histórica da associação entre meios têxteis, mão de obra feminina e trabalho mais alienado do que propriamente inventivo. Tai Smith sintetiza muito bem tais oposições:

A história da tecelagem como uma forma de labor, e de atividade feminina, tornou-se aparentemente indissociável do meio em si mesmo. Enquanto a pintura, como atividade livre, podia ser vista como algo que transcendia a divisão do trabalho, a prática da tecelagem só poderia ser compreendida no interior das determinações econômicas. É claro que a pintura deve ocupar um terreno social. Já este pode ser definido como masculino, em contraste

24 SMITH, Tai. Pictures made of wool: the gender of labor at the Bauhaus Weaving Workshop (1919-1923). Invisible Culture: an electronic journal for visual culture, New York, n. 4, spring 2002. Disponivel em: <http://www. rochester.edu/in_visible_culture/Issue4-IVC/TSmith.html>. Acesso em: 16 jul. 2007. (Tradução minha).

25 A este respeito consultar, WELTGE, Sigrid Wortmann. Women's work. Textile art from the Bauhaus. Londres: Thames and Hudson, 1993. p. 98-99. 
daquele feminino, que é a prática da tecelagem. Assim, ainda que classe e labor sejam termos sexuados, a tecelagem é feminilizada porque sua prática representa o labor, e nada além disso. ${ }^{26}$

Também no Brasil as associações valorativas entre meios têxteis e práticas femininas encontraram respaldo. Em um texto assinado por Pietro Maria Bardi, dedicado à introdução do art déco no Brasil e à contribuição da família Graz-Gomide, as lógicas de gênero associadas ao valor artístico do produtor e seus efeitos sobre os produtos aparecem de modo exemplar:

São eles (John e Regina Graz e Antonio Gomide) os lídimos precursores e principais fautores da arte decorativa no Brasil. Claro que não se limitaram a isto (com a possivel exceção de Regina Graz). Transcenderam a arte decorativa e criaram ainda [...] inúmeras obras de grande valor artístico. ${ }^{27}$

As obras de Regina Gomide Graz são descritas como arte sem grande valor estético por não terem sido capazes de transcender sua condição de aplicabilidade. Ou seja, são associadas a um trabalho mais comercial e menos puro, espiritual ou artístico do que o de seus companheiros. Em suma, tratava-se de labor e não de arte. Seguindo a lógica de desenvolvimento classificatório já mencionada, a produção têxtil era naturalizada como feminina, artesanal e pouco intelectualizada.

Dentro das parcerias artísticas e familiares vividas por Regina Graz com seu marido e seu irmão, parecia "natural” que aos homens coubesse a produção mais séria e durável, como as pinturas e os móveis, e às mulheres os objetos mais decorativos e pereciveis, como as costuras, as almofadas e os tapetes. 0 próprio material ao qual Regina dedicou-se - o têxtil - não apenas era menos valorizado do que os demais, como também sua parca durabilidade contribuiu para que o tempo levasse sua importância junto com as próprias obras ${ }^{28}$.

26 SMITH, Tai. Pictures made of wool: the gender of Labor at the Bauhaus Weaving Workshop (1919-1923). Invisible Culture: an electronic journal for visual culture, New York, n. 4, spring 2002. Disponível em: <http://www. rochester.edu/in_visible_culture/Issue4-IVC/TSmith.html>. Acesso em: 16 jul. 2007. (Tradução minha).

27 BARDI, Pietro Maria. A família Graz-Gomide. In: A FAMÍLIA Graz-Gomide. 0 artdeco no Brasil. São Paulo: Museu Lasar Segall, 1976. p. 5-6. Catálogo de exposição.

28 Em entrevista, John Graz mencionou o fato da arte têxtil de Regina ter desaparecido. "Infelizmente, sua arte se desfez, nos tapetes, nas decorações, nos ambientes que criou, quantas vezes comigo, e que o tempo desfez". GRAZ, John. Entrevista. Folha de São Paulo, São Paulo, 30 fev. 1980. 
A opção pela arte têxtil, e os efeitos dessa escolha, precisam ser compreendidos dentro de um contexto internacional de redefinição das hierarquias entre os gêneros, artísticos e sexuais, e, também, pelas injunções sociais e culturais locais ${ }^{29}$. Mas cabe ressaltar que mesmo do ponto de vista da participação masculina na empreitada, a escolha da decoração como meio ou projeto artístico estava longe de ser comum, afinal, a própria idéia de um "decorativismo" foi sendo combatida pelas vanguardas artísticas do século XX como um elemento superficial, fútil e comercial da arte, o qual precisaria ser extirpado ${ }^{30}$. Se o estatuto da decoração como forma de arte era ainda incerto nos países centrais, quanto mais no Brasil. De onde então a dupla de artistas teria retirado suas inspirações para a conversão das carreiras nessa direção?

\section{Decoração como arte total: os estudos de formação na École des Beaux Arts de Genebra}

A opção da dupla John-Regina pela atuação no campo das artes decorativas deveu-se, segundo depoimentos do autor, a contingências financeiras ${ }^{31}$. Para além disso, é importante ressaltar o peso determinante que teve o período de formação de ambos, em inícios do século XX, na École des Beaux Arts de Genebra. Diferindo de outras tradições artísticas nacionais nas quais o peso da hierarquia dos gêneros relegava às artes decorativas um papel secundário, em toda a Suíça as artes aplicadas desfrutaram de grande prestígio, ao menos desde finais do século XIX. Com as exposições universais, o país encontrava-se comprimido, de um lado, pela produção de luxo francesa, cuja superioridade qualitativa era notável e, de outro lado, pelas obras alemãs, cuja relação intima e fértil com a indústria acarretava uma produção em larga escala, muito mais adaptada a um mercado que se mundializava. Ciente dos perigos econômicos e culturais advindos da baixa competitividade dos produtos suíços no mercado externo, o governo

29 Sobre a relação entre a arte têxtil e as mulheres no começo do século que vem sendo investigada por algumas historiadoras da arte vale citar o artigo de BOYDELL, Christine. Free-lance textile design in the 1930s: an improving prospect? Journal of design history, v. 8, n. 1, p. 27-42, 1995.

30 A este respeito, consultar HARRISON, Charles. Abstração. In: HARRISON, C.; FRASCINA, F.; PERRY, G. (Org.). Primitivismo, cubismo, abstração. Começo do século XX. São Paulo: Cosac \& Naify, 1996. p. 204.

31 Tal afirmação é feita por vários artigos que abordam a trajetória do artista, como: JOHN Graz: o último pintor da Semana de 22. Manchete, Rio de Janeiro, n. 1491, nov. 1980; JOHN Graz: o homem que levou o futurismo para a sala de visitas. Jornal da Tarde, São Paulo, 29 mar. 1980. 
começou a investir nas artes aplicadas, fundando escolas técnicas e promovendo concursos e premiações nessa área, a partir de 1884. Foi nesse momento que os embates estéticos entre as "duas Suiças” atingiram o auge. Genebra, em função de sua situação geográfica, inspirou-se no exemplo francês, ao passo que a Basiléia e Zurique seguiram o modelo das academias alemãs. De um modo geral, a arte na Suiça românica adquiriu uma feição mais tradicional, ao passo que na Suiça alemã o espírito reinante foi o de uma abertura às inovações artísticas e também tecnológicas ${ }^{32}$.

Em 1913, ano em que a família Gomide desembarcou na Europa e inscreveu seus filhos na École des Beaux Arts de Genebra, o debate acima descrito era bastante acirrado, perpassando todo o campo artístico, o que envolvia, evidentemente, as instituições dedicadas ao ensino das artes, dentre elas a EBA, principal escola de formação de artistas do cantão de Genebra. Isso pode ser vislumbrado na diversidade com que foi grafado o próprio nome da instituição. Nas referências aos artistas disponíveis no Brasil, encontrei sempre a menção de que estudaram na "École des Beaux Arts et Arts Appliqués de Genève"; entretanto, o nome oficial da escola é apenas "École des Beaux Arts de Genève”. Acredito que o engano não seja acidental, mas guarde um sentido cultural.

Basta que se observe o programa da escola para constatar que as artes ditas aplicadas ocupavam metade dos cursos oferecidos pela instituição ${ }^{33}$. Ou seja, contrariando o modo como geralmente se concebe o currículo de uma escola de belas artes, ao menos a partir de uma tradição francesa na qual as artes aplicadas ocupavam uma pequena parcela da formação - mais voltada para a pintura, a escultura e a arquitetura -, na Suiça românica as distinções e hierarquias de prestígio entre as modalidades eram muito menores, e, talvez mesmo possa-se afirmar inexistentes. Deste modo, no momento de formação de Regina Gomide as artes decorativas ocupavam um lugar simbólico de prestígio no campo artístico local, o que se traduzia, dentro da École des Beaux-Arts de Genebra, em um currículo versátil que englobava tanto disciplinas voltadas para as artes tradicionais como outras

32 Para maiores informações sobre a arte na Suiça no período abordado consultar, PALLINI, Stephanie. Entre modernisme et tradition: la Suisse romande l'entre deux-guerres faces aux avant-gardes. Berna: Betelli Verlags, 2004.

33 Embora ao longo do tempo as disciplinas e professores tenham se transformado um pouco, durante a década de 1910 eram as seguintes classes que compunham a grade curricular da EBA: Classe préparatoire; Classe de perspective; Classe d'architecture; Classe d'ornement; Classe de modelage; Classe d'anatomie; Classe de figure A; Classe de figure B; Classe de Figure C; Classe de composition décorative; Classe de figure décorative. Documentation sur l'École des Beaux-Arts de Genève. Archives de l'Etat de Genève, Section de la Terrasière, Código 1992 va 32.85 Enseignement. 
dedicadas às artes aplicadas. Havia mesmo uma classe especialmente voltada à formação de artistas-tapeceiros, concebidos como desenhistas de superfícies decorativas.

A opção pelas artes aplicadas era plenamente compreensível naquele contexto. Por um lado, pela notoriedade que o gênero desfrutava no campo artístico no qual a dupla se formou, o que possibilitou a adoção e o cultivo de valores e práticas específicos. Por outro, a esse fator somaram-se condições objetivas do meio artístico brasileiro, acanhado e dependente de uma pequena elite de consumidores de obras ${ }^{34}$, grupo este ao qual Regina pertencia por afinidade, dado o circuito social engendrado por sua família, que se traduzia em potenciais clientes ${ }^{35}$. Assim, tanto no caso de Regina como no de John, é possível aferir que a reconversão da carreira de artista "puro" para a de "artista decorador" explica-se pela somatória de todos esses fatores mencionados.

É importante assinalar que a produção por eles realizada foi verdadeiramente pioneira no que tange à implantação do art déco entre nós. Os projetos decorativos revelam uma extraordinária visão de conjunto dos ambientes e pode-se mesmo dizer que estavam à altura dos mais refinados exemplares exibidos nos Salons des Artistes Decorateurs de Paris. Um exemplo da integração e harmonia dos conjuntos formulados pelo casal nos é dado pela residência de Mário da Cunha Bueno, projetada em finais dos anos 20. Nela, as mesmas linhas geométricas são repetidas na porta, nos vitrais, nos móveis, cortinas e almofadas, garantindo uma unidade completa entre todos os elementos que compõem a sala. Como em vários trabalhos efetuados pelo par, a concepção geral, os móveis, luminárias e portas ficaram a cargo de John Graz, enquanto os tapetes, almofadas e cortinas foram executados por Regina Gomide (ver Fig. 1 e 2).

Dentre os tipos de art déco existentes, a dupla havia escolhido uma das duas vertentes que eram conhecidas e estavam em disputa na Suíça, no período em que lá estudaram. Grosso modo, o panorama pode ser assim descrito: na Suiça francesa, as artes decorativas inclinaram-se para obras figurativas, artesanalmente finas, manuais, realizadas com materiais luxuosos e voltadas para clientelas exclusivas. Seguiram, portanto, certa tradição segundo a qual o artista-decorador ocupava o nobre papel de "mentor" inte-

34 A esse respeito consultar JOHN Graz: o último pintor da Semana de 22.

Manchete, Rio de Janeiro, n. 1491, nov. 1980.

35 Os principais clientes da "família Graz-Gomide" foram: Roberto Simonsen, Caio Prado, Rafael Noschese, Godoy Moreira, Mario Cunha Bueno e a família Jafet. Sobre os projetos decorativos, consultar: SÃO PAULO (Estado). Secretaria da Cultura. Reminiscências do modernismo: John Graz. São Paulo: Fundação Padre Anchieta, 1980. 
lectual de uma produção cuja maestria culminava em peças admiradas como obras de arte únicas. Já na Suiça do norte, fortemente inspirada no modelo alemão, as artes decorativas tomaram um rumo oposto: arte e indústria caminharam juntas. Isso significava a adoção de padrões estilísticos mais simples, abstratos, facilmente adaptáveis à produção (e ao consumo) em larga escala. Tal orientação, mais adequada aos tempos modernos, era perceptível nos primeiros anos da Bauhaus e, particularmente no caso dos têxteis, à produção de Sophie Tauber-Arp, cujos tapetes e tecidos realizados durante os anos 1910 e 1920 traziam padrões abstratos, que favoreciam sua produção em larga escala. 0 artista, segundo tal concepção, deixava de trabalhar para um cliente único e conhecido, tornando-se um "funcionário da indústria”, um designer ${ }^{36}$.

No momento da formação de Regina Gomide, eram essas as concepções em disputa. 0 modelo alemão era então percebido como mais moderno e economicamente ajustado ao capitalismo, mas estava longe de ser consensualmente bem visto entre os artistas. As críticas a ele endereçadas alegavam que ao tornar-se um funcionário do capital, o artista abria mão de sua missão primordial: realizar uma obra de arte única. Com isso, era responsável por dois lastimáveis declínios: o do objeto, que com a massificação perdia sua "aura"; e o de seu próprio criador, que de artista tornava-se designer. Pode-se supor que Regina Gomide (bem como seu irmão Antonio Gomide e seu futuro marido John Graz) tenha sido afetada pelos embates estéticos de seu tempo, que envolviam também tendências estilísticas em disputa. Os estudos na École des Beaux Arts de Genebra deixaram marcas em boa parte de sua carreira posterior na medida em que, tal como o campo local preconizava, sua opção foi também por um art déco de orientação francesa, ou seja, calcado em produções únicas, exclusivas e elegantes realizadas por artistas-decoradores de alta qualificação técnica e estética para uma clientela seleta, mantendo assim o culto da obra de arte única e aurática. Há, portanto, adequação entre suas opções posteriores e os discursos predominantes na instituição de formação.

Posições, disposições e escolhas artísticas: a atuação de Regina Gomide Graz no campo brasileiro

E qual era o estatuto das artes têxteis na Suiça? Eram elas vistas como artes "femininas"? A correlação entre artes têxteis

36 A este respeito consultar o artigo de BONZON, Gael. Rapports entre la creation artistique textile genevoise et l'Art Déco de 1917 à 1940. Genava. Revue d'histoire de l'art et d'archeologie, Musée d'Art et d'Histoire La Baconnière, Genebra, p. 179-202, 2003. 
e prática feminina, como já foi dito, achava-se em pleno vigor na Bauhaus, cujo raio de atuação era fortíssimo nos cantões que compunham a Suiça germânica, no mesmo momento em que Regina concluía seus estudos na "outra" Suiça. No que se refere a esta, embora sejam raros os estudos sobre a condição da mulher artista ${ }^{37}$, as fontes de época revelaram uma predominância de mulheres expondo obras em suportes de tecidos nos salões genebrinos ${ }^{38}$. Além deste, há outros indícios. Em 1911, Hélène de Mandrot inaugurou uma escola de bordado em seu castelo - denominada Maison des Artistes de La Sarraz - no mesmo período em que Nora Gross fundou em Lausanne uma Sociedade de Arte Doméstica, ambas destinadas a um público feminino, visando propagar um "artisanat de bon gôut”. Nas escolas, pregava-se uma reabilitação dos modos de fazer tradicionais (em oposição à produção mecânica), com o que se reafirmavam vínculos também morais: os trabalhos de decoração e de bordados eram concebidos como essencialmente humildes, simples, femininos e, por fim, domésticos ${ }^{39}$.

Mas onde a posição subalterna das mulheres e de seu campo análogo - o das artes femininas - fazia-se mais visível era dentro da L'Oeuvre, a mais importante associação dos artistas da Suiça francesa, inaugurada em 1913. Entre seus 87 membros fundadores, apenas 9 pertenciam ao sexo feminino, todas elas

37 Há realmente poucos textos dedicados às relações entre arte e gênero na Suiça francesa. Mesmo no que diz respeito aos espaços de formação reservados às mulheres sabe-se muito pouco. Com base na documentação lida pode-se afirmar que na École des Beaux Arts de Genebra a maior parte das turmas e disciplinas eram mistas, muito embora a obrigatoriedade do ensino misto só tenha se efetivado em 1920. Até essa data, no primeiro ano havia turmas separadas, o que tendia a se dissolver nos anos seqüentes. Para maiores informações sobre a formação na escola consultar: Rapports École des Beaux-Arts, 1910-1925. Archives de la Terrasièrre, cod. Va 32.55 e também a monografia de FERNANDEZ, Nancy. Balade au coeur de la formation artistique à l'École Supérieure des Beaux-Arts de Genève. 2005. Memoire, ESBA- Haute École D’Art Visual, Genebra.

38 Os catálogos comprovam que a grande maioria dos expositores de artes decorativas, dedicados aos têxteis, a atuarem nos salões genebrinos de inícios do século era composta por mulheres. Dentre elas destacaram-se Helène de Mandrot, Nora Gross, Marguerite Naville, Mathilde do Canto etc. Para tal afirmação baseio-me na pesquisa por mim realizada nos catálogos das principais exposições artísticas ocorridas em Genebra, entre 1914 e 1920. Entre elas cito: Premier Salon Genevois. Galerie Moss, 1914; Deuxième Salon Genevois. Galerie Moss, 1919: exposition suisse des beaux arts. Galerie Moss, 1918. Cabe notar, porém, que o mais importante artista têxtil modernista de então era um homem: Percival Pernet. A este respeito consultar BONZON, Gael. Rapports entre la creation artistique textile genevoise et l'Art Déco de 1917 à 1940. Genava, Revue d'histoire de l'art et d'archeologie, Musée d'Art et d'Histoire La Baconnière, Genebra, p. 179-202, 2003.

39 Sobre a trajetória de Helène de Mandrot e sua intervenção no campo artístico genebrino, consultar: BAUDIN, Antoine. Hélène de Mandrot et la Maison des Artistes de La Sarraz. Lausanne: Editions Payot, 1998. 
alocadas em um mesmo nicho, o dos "Trabalhos domésticos" ${ }^{\text {. }} 0$ diretor explicava tal desígnio, asseverando que seria preciso

energia, ombros fortes para suportar a tarefa ingrata. Por cortesia e por educação para com as senhoras nós as dispensamos de tal infortúnio [...] Nós desejamos assegurar às mulheres um campo de atuação dentro das 'Artes domésticas'. Nós pensamos que elas terão mais alegria de trabalhar aí. ${ }^{41}$

Porém, ainda que as artes têxteis fossem comumente associadas às produções femininas e estas fossem geralmente rotuladas como trabalho doméstico, logo inferior, havia honrosas exceções. 0 exemplo de Sonia Delaunay, que desde 1914 direcionara com muito êxito sua carreira de pintora para a produção de tecidos, vestidos, estamparias e tapetes em art déco, era bastante conhecido e estimulante ${ }^{42}$. Dentro da própria Suiça românica, havia um outro modelo feminino instigante: o da artista cubista Alice Bailly que, após atuar por anos em Paris, retornou ao lar durante a Guerra, momento inaugural de uma fase em que utilizou de modo extremamente inovador os tecidos e lãs em seus mais de 50 "tableauxlaines". Nestes, experimentou os efeitos particulares dos materiais, com o que logrou transgredir os sentidos que lhes eram geralmente atribuídos: não se tratava de arte aplicada, nem de decoração, posto que seu trabalho mantinha-se dentro do domínio das belas artes, ou seja, da arte pura, porém com telas feitas a partir de materiais impuros, como as lãs e as linhas, tradicionalmente associadas às artes menores e femininas ${ }^{43}$.

40 Dentre aquelas mencionadas nos manuscritos da "Première Assemblée

Générale”, realizada por ocasião da fundação da entidade, estão justamente as artistas anteriormente mencionadas, e outras, também dedicadas às artes aplicadas e às artes têxteis. "Les travaux doméstiques seront soignés particulièrement par les dames de l'association. Elles s'entournerons des documents, enqueteront en ferant rapports sur les travaux faits jusqu'ici sous l'égide des mesdames de Mandrot, Mecis, Balland etc. Elles organiseront alors des expositions de ces travaux, elles en tirerons des déductions pour l'amélioration de l'enseignement. Son spécialement designées pour cette tâche. Mmes Bedos Didati Balland; Porto-Mattey; Dora Gross; de Mandrot; de Mercies; Reuttes-Junot; Perrochs; Goering (...)”. Cahiers de L'Oeuvre. Manuscript. Première Assemblée, Générale, 09 nov. 1913. Documento pertencente aos Archives Cantonales Vaudoises. Section Archives Privés, PP 007.

41 BAUDIN, Antoine. Hélène de Mandrot et la Maison des Artistes de La Sarraz. Lausanne: Editions Payot, 1998. p. 25. (Tradução minha).

42 Sobre a trajetória da artista consultar: SANDOR, Kuthy (Org.). Sonia \& Robert Delaunay: dialogues d'artistes-résonances. Berna: Kunstmuseum, 1992.

43 JACCARD, Paul-André. Alice Bailly. La fête étrange. Lausanne: Musée Cantonal des Beaux-Arts de Lausanne, 2005. 
Para além desses exemplos citados, representados por artistas de "vanguarda", verificam-se casos de artistas mais conservadoras, animadas por um projeto em nada tímido: o de regenerar os interiores de todos os lares da nação. Segundo Antoine Baudin, tratava-se, mesmo que de modo eufemizado, de um plano bastante ativo de intervenção no campo artístico. As artes decorativas funcionavam, nesse sentido, como um substituto possível para as mulheres daquela que era, entre todas, a arte considerada então como a mais poderosa - visto que mais completa - a arquitetura. Como ele afirma,

[...] mesmo que de maneira muito eufemizada, essa vontade de investir no interior confere uma dimensão significativa à própria noção de Arte doméstica, em uma relação de paralelismo ou de complementariedade àquela de Arquitetura doméstica, na qual permaneciam confinadas naquele momento as rarissimas mulheres que tentaram intervir diretamente no campo da arquitetura. ${ }^{44}$

A escolha de Regina Gomide Graz pela atuação como "colaboradora" de seu marido nos projetos decorativos, "executando" apenas os gêneros mais "femininos", ou seja, as obras têxteis que vestiam e adornavam os ambientes, comportava, a partir do que foi dito, algumas ambigüidades. Por certo, coadunava-se com expectativas socialmente difusas sobre o papel social aceitável, e mesmo desejável, para uma artista mulher de elite, casada com outro artista. Nada indica que ela rivalizasse com seu cônjuge; pelo contrário, Regina e John parecem ter endossado a imagem - que tanto agradava aos críticos - de uma dupla em perfeita sintonia, cuja produção resultava "harmônica" 45 . 0 fato de tratarse de um trabalho passivel de ser realizado no âmbito do próprio lar e com instrumentos historicamente feminilizados, como os materiais têxteis, as linhas e as agulhas, mantinha-na no limite de atuação apropriado: a arte doméstica.

44 No original: “[...] même très euphémisée, cette volonté d'investir l'intérieur donne une dimension significative à la notion même d'Art domestique - comme em relation de parallélisme ou de complémentarité avec celle d'Architecture domestique, où restent confinées au même moment les rarissimes femmes qui [...] entendent intervenir directement dans le champ architectural." BAUDIN, Antoine. Hélène de Mandrot et la Maison des Artistes de La Sarraz. Lausanne: Editions Payot, 1998. p. 22

45 A este respeito, consultar o primeiro capítulo de minha tese de doutorado, SIMIONI, Ana Paula Cavalcanti. Amadora, condição feminina: a crítica de arte e as representações sobre as mulheres artistas brasileiras. In: Profissão artista: pintoras e escultoras brasileiras entre 1884 e 1922. 2004. 296 f. Tese (Doutorado em Sociologia) - Faculdade de Filosofia, Letras e Ciências Humanas, Universidade de São Paulo, São Paulo, 2004. 
Todavia, há dissonâncias nessa trajetória. Em primeiro lugar, o sucesso da produção da artista permitiu-lhe inaugurar inicialmente um ateliê no qual empregou várias moças. Com o êxito contínuo, inaugurou, nos anos 1940, uma indústria de tapetes, a Indústria Regina Graz, a qual permaneceu ativa até 1957 - quando, incapaz de concorrer com uma produção plenamente industrial, teve seu maquinário vendido para as Fábricas Parahyba ${ }^{46}$. Ou seja, a arte de Regina Graz transcendeu os limites da produção doméstica, autonomizando sua produção em relação à de John Graz, fato que se evidencia pelo próprio nome da empresa, que era o seu e não o dele. A figura 4 é um bom exemplo da produção da artista no período posterior aos anos "históricos" da introdução do art déco. Nos idos de 1940 e 1950, seus tapetes haviam adquirido um caráter mais padronizado e, em muitos casos, mais abstrato, respondendo às exigências de produções menos exclusivas e artesanais, embora não se tratasse ainda de uma produção massificada em grande escala. Cotejando uma obra desse período com uma tapeçaria realizada nos anos 20 (Fig. 3), torna-se evidente a paulatina simplificação dos motivos, certa tendência à abstração e mesmo uma transformação do próprio material, outrora mais sofisticado e dependente de uma artesania fina.

Mesmo antes, no período mais fecundo de atuação da dupla John-Regina, na época áurea do art déco, os anos 1920 e primórdios dos 30, é possível compreender, apoiando-nos em sugestões de Antoine Baudin ${ }^{47}$, a propensão para a produção decorativa não como fruto de um fracasso, relacionado à precariedade do campo, mas sim como um projeto alicerçado em posições estéticas interiorizadas no período de formação genebrino - projeto de intervenção e regeneração dos lares. Nesse sentido, a dupla John-Regina Graz havia atuado, decisivamente, no sentido da implementação de um novo gosto e de uma nova prática: a arte realizar-se-ia não apenas nos distantes e consagrados espaços dos museus e galerias, mas também por meio daqueles objetos cotidianos e domésticos. Pode-se afirmar que, nesse sentido, praticaram uma concepção de arte bastante original para o contexto brasileiro, a qual transcendia as esferas institucionalizadas. A idéia de uma arte total, tão presente na Suiça, se realizaria predominantemente pela arquitetura, a rainha das artes, a qual era capaz de acoplar, em seus interiores, as demais manifestações, como a pintura, a escultura, a jardinagem e a decoração. Entre nós, tal concepção teve

46 CÁURIO, Rita. Artêxtil no Brasil: viagem pelo mundo da tapeçaria. Rio de Janeiro: Ed. do Autor, 1985.

47 BAUDIN, Antoine. Hélène de Mandrot et la Maison des Artistes de La Sarraz. Lausanne: Editions Payot, 1998. 
seu auge com a célebre Casa Modernista, concebida por Gregori Warchavchik e inaugurada em 1927 na rua Santa Cruz, projeto que contou com a participação de John e Regina Graz, ele como moveleiro e ela como artífice das decorações em tecidos.

A atuação de Regina foi decisiva para a implantação de um novo gosto e de um novo estilo, bastante modernos, capazes de alçarem as criações têxteis à condição de gênero artístico autônomo, equivalente aos demais. Se nem sempre o tempo, os críticos e os historiadores da arte foram capazes de reconhecer sua contribuição, tal fato ocorre como conseqüência das próprias categorias com que são tradicionalmente julgadas as produções têxteis, associadas a objetos artesanais e femininos. Conforme pretendi demonstrar, a associação entre os três termos determinou posições desiguais dentro de um campo que foi, e ainda é, pautado por uma hierarquia dos objetos, tida como natural e esteticamente determinada ${ }^{48}$. 0 caso das artes têxteis permite perceber o quanto a história da arte assenta-se sobre uma prática discursiva perpassada pelas dimensões do gênero. A trajetória de Regina Graz é indicativa do quanto a história social da arte precisa proceder à crítica das suas próprias categorias e juízos analíticos caso proponha-se a compreender a produção das artistas mulheres e as razões dos juízos e percepções que as relegam a posições secundárias.

48 Pierre Bourdieu já demonstrou o quanto a idéia de que existe uma percepção estética "pura" é um produto da própria história do campo artístico em direção de sua autonomização. BOURDIEU, Pierre. A gênese histórica de uma estética pura. In: O poder simbólico. Tradução Fernando Tomaz. 3. ed. Rio de Janeiro: Bertrand Brasil, 2000. p. 281-298. 
Figura 1: Residência de Mário da Cunha Bueno. Sala. Foto Instituto John Graz.

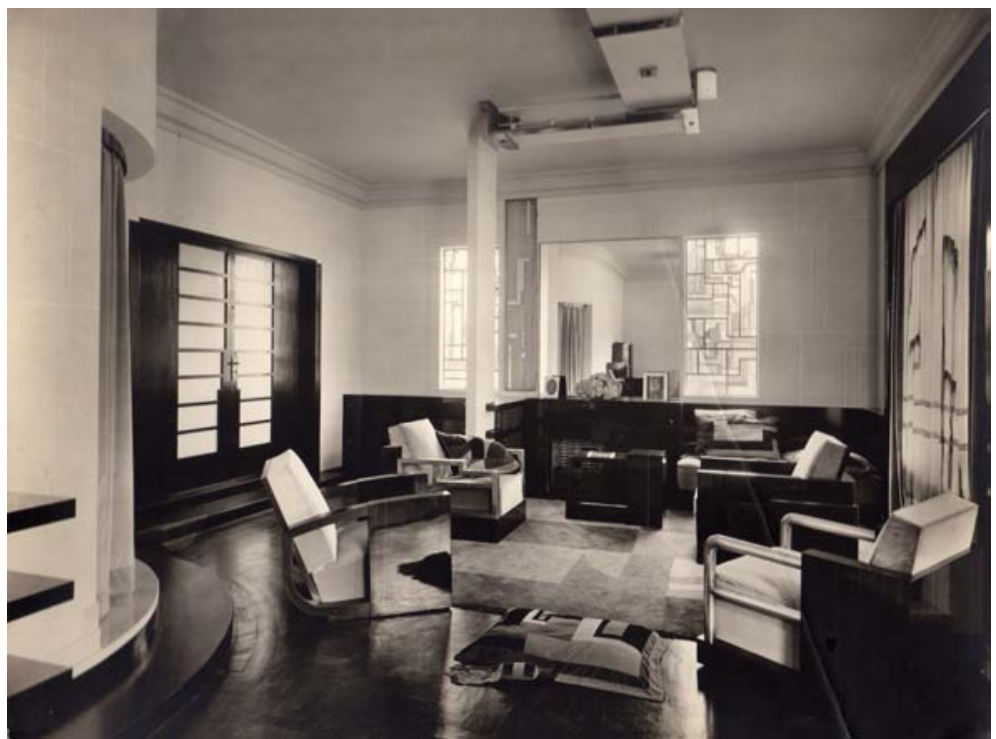


Figura 2: Detalhe de almofada e tapete realizados por Regina Gomide Graz para a residência de Mário da Cunha Bueno. Foto Instituto John Graz.

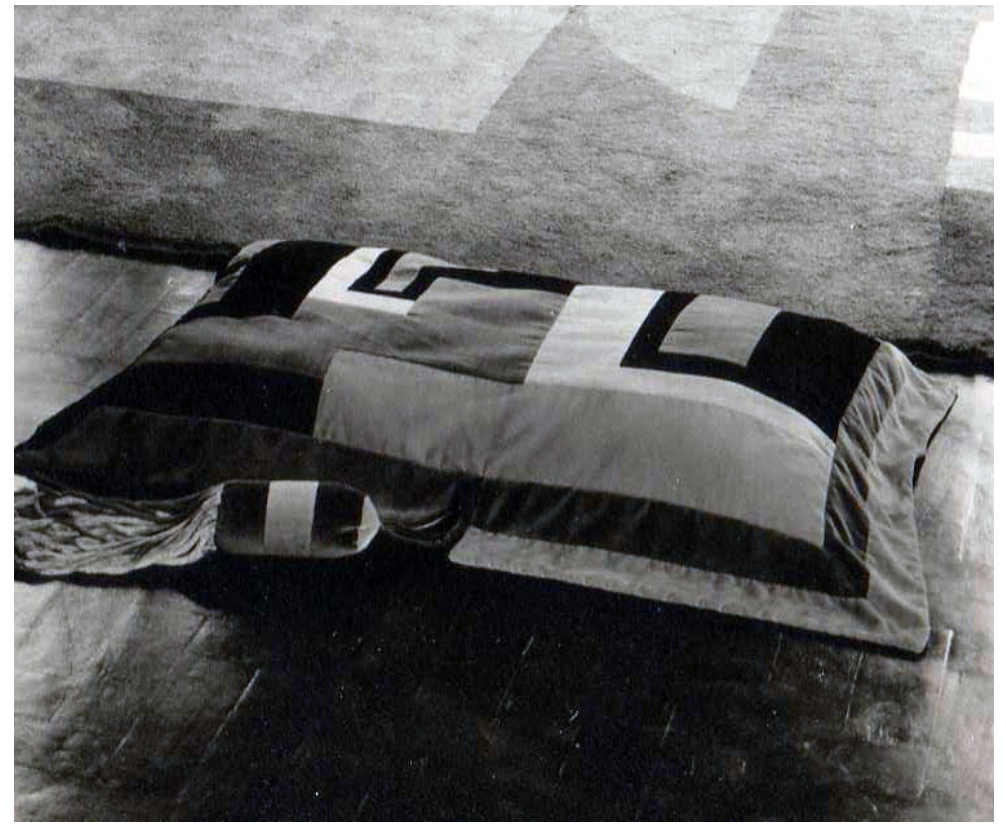


Figura 3: Foto de Tapeçaria de Regina G. Graz Anos 20. Arquivo Instituto John Graz.

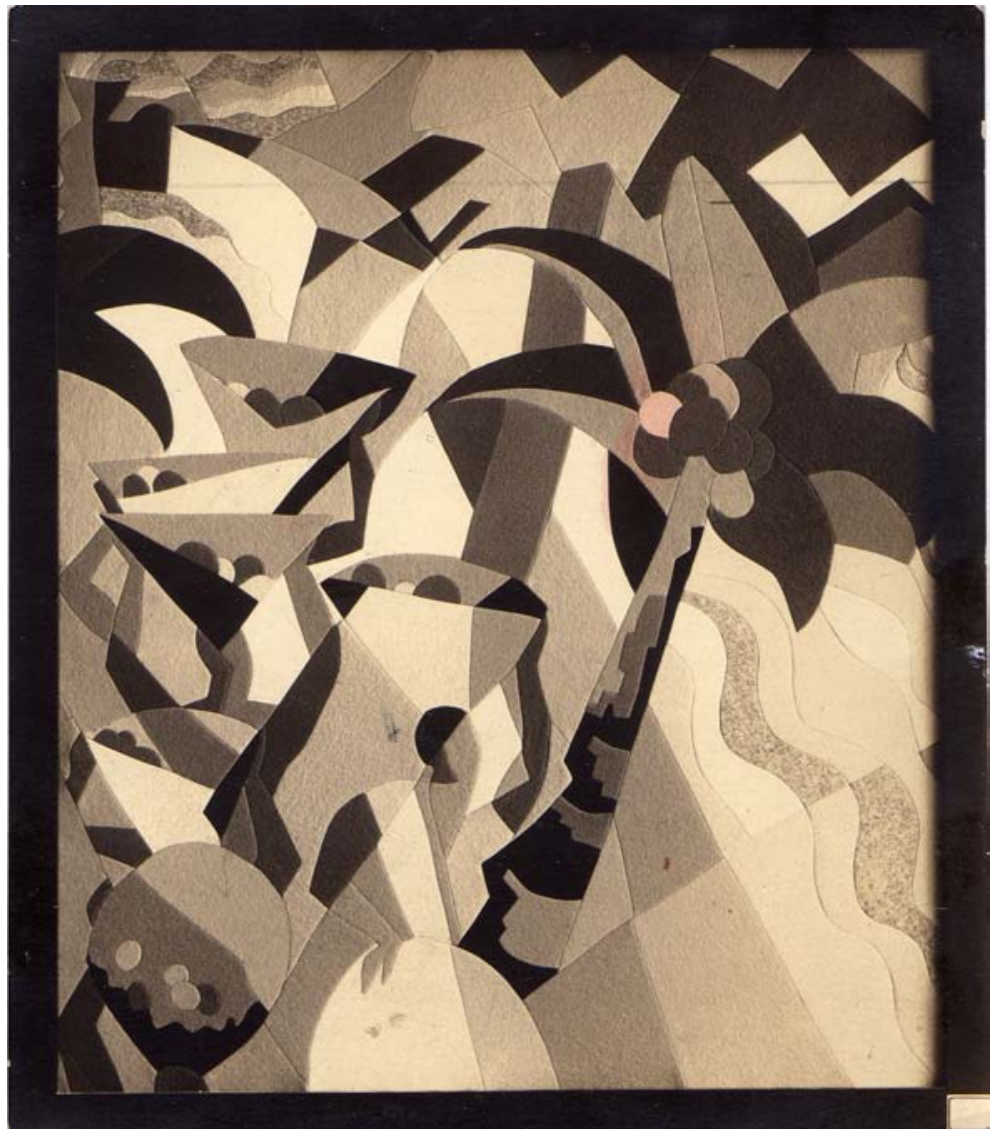


Figura 4: Foto de Desenho para Tapete, provavelmente do mostruário da "Fábrica Regina Ltda", Anos 40. Arquivo Instituto John Graz.

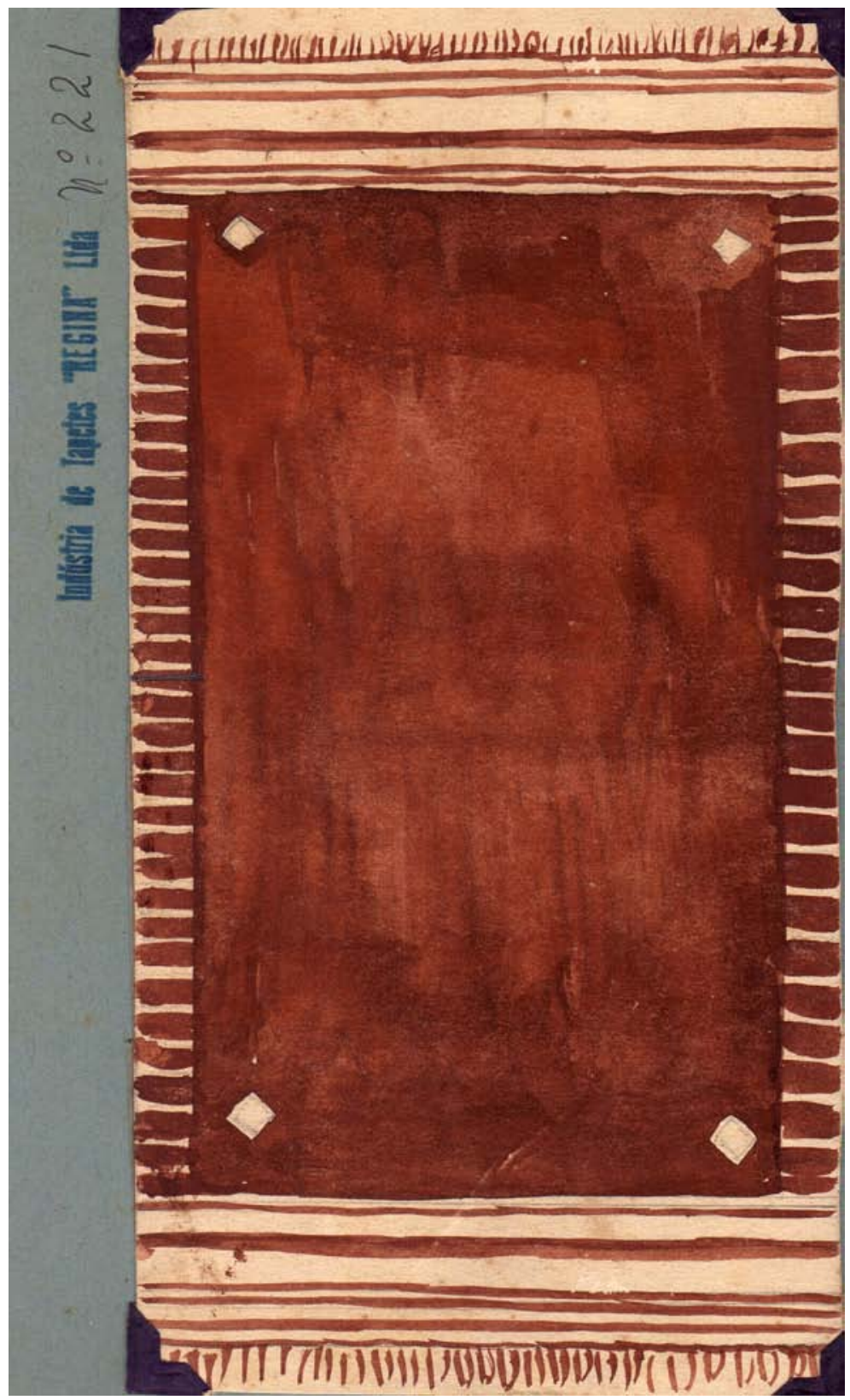

